\title{
Smallholders Use of Weather Information as Smart Adaptation Strategy in the Savannah Area of Ondo State, Nigeria
}

\author{
Rasheedat Alliagbor, David Olufemi Awolala, and \\ Igbekele Amos Ajibefun
}

\section{Contents}

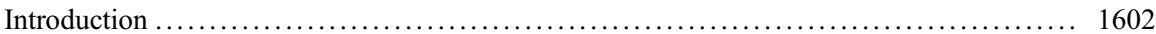

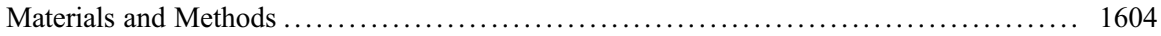

Econometric Model ..................................................... 1605

Heckman Two-Step Procedure .......................................... 1605

Results and Discussions ................................................ 1607

Drivers of Farmers' Use of Weather Information for Smart Decisions ................. 1607

Conclusions and Policy Recommendations .................................... 1608

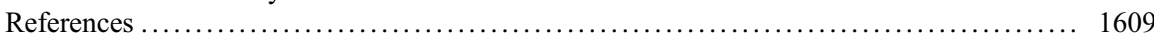

\section{Abstract}

Weather information is needed for smart decisions because uncertainties in weather phenomena are beyond capacity of smallholders for autonomous responses. The study analyzed determinants of farmers' use of weather information as smart adaptation strategy. Arable crop farmers were sampled in the derived

This chapter was previously published non-open access with exclusive rights reserved by the Publisher. It has been changed retrospectively to open access under a CC BY 4.0 license and the copyright holder is "The Author(s)". For further details, please see the license information at the end of the chapter.

\section{R. Alliagbor $(\bowtie)$}

Department of Agricultural and Resource Economics, Federal University of Technology Akure, Akure, Ondo, Nigeria

e-mail: jessicaalliagbor@gmail.com

D. O. Awolala

African Climate Change Leadership Program (AfriCLP), University of Nairobi, Kenya and Institute of Resource Assessment, University of Dar es salaam, Dar es Salaam, Tanzania

e-mail: ddawolala@gmail.com

\section{A. Ajibefun}

Department of Agricultural Economics and Rural Sociology, Auburn University, Auburn, AL, USA e-mail: iajibefun@yahoo.com 
savannah agro-ecology area of Ondo State, Nigeria. Heckman probit model estimates show that gender and agricultural extension services were significant positive drivers of farmers' access to weather information. Should weather information becomes an alternative adaptation strategy, access to credit was found as the major driver of farmers' propensity to use weather information before taking climate smart agricultural decisions. Further results reveal that increasing knowledge of onset date, large farm size, and access to agricultural extension services significantly reduced farmers' propensity to use improved weather information for smart decisions in the dry savannah area.

\section{Keywords}

Extreme weather $\cdot$ Weather information $\cdot$ Adaptation responses $\cdot$ Smart decisions $\cdot$ Heckman Probit $\cdot$ Ondo State

\section{Introduction}

Climate change is a particular threat to continued economic growth and livelihoods of vulnerable populations (UNEP 2018). The United Nations Development Programme (2011) confirms that Africa faces considerable challenges in adapting to the long-term impacts of climate change and extreme climate events. Extreme events have led to severe economic losses over the years and have increase farmers' needs for weather forecast information that will enable predictions beyond the timeline of indigenous knowledge in decision-making processes. Agricultural stakeholders have to contend with the high vulnerability due to low levels of adaptive capacity and poor weather services across many developing economies. Ensuring that decision makers and end users especially smallholders are able to respond to the medium- and-long-term implications of climate change is important in promoting climate-resilient development (Ziervogel and Zermoglio 2009).

Jones and Carabine (2013) observed that the need for medium- and long-term climate information to support climate-resilient development planning in Africa is clear to generate long-term strategies for loss and damage, adaptation finance, climate resilient agricultural practices, and other variants such as climate-compatible development. In the Sub-Sahara Africa, farming systems are highly reliant on prevailing environment, and the existence of traditional knowledge offers elements of resilience (FAO 2011).

In managing the adverse impacts of extreme climate events and climate variability, local farmers have to adjust to harsh weather conditions by relying on weather forecast services which would help moderate potential damage and adverse consequences. The accessibility and usefulness of weather information are therefore critical factors that will affect farmer's ability to adapt (Alston 2013; Serna 2011; Bryan et al. 2009).

In Nigeria, the agricultural production system is predominantly rain-fed, hence highly vulnerable to seasonal variability which affects agricultural livelihood of 
smallholders and landless laborers who depend on agriculture, as one of the most vulnerable countries among developing African economies (Vermeulen et al. 2012). The impacts of long droughts and deficit rainfall will be mostly felt by the rural population who represent over $80 \%$ of the Nigerian population who have less means to adapt and/or diversify their livelihoods (World Bank 2013). Nigeria may lose about $11 \%$ of GDP ( $\$ 460$ billion) to drought risk event by 2020 and about $25 \%$ by 2050 .

Smallholders usually depend on traditional weather predictions in taking production decisions (Mugabe et al. 2010). A variety of traditional indicators have been developed in taking decisions weather-dependent farm management decisions. Over time, some traditional weather and climate indicators consequently are no longer patterned base on existing climate behavior (Sanni et al. 2012). Variability in weather parameters has resulted into significant changes in agricultural production cycle such that farmers can no longer accurately predict start and duration of rainfall seasons by relying on indigenous knowledge (Awolala 2018; Madzwamuse 2010). Weather information has shown potential for improving resilience of agriculture to climate shocks and uncertainty, as a fundamental basis upon which smallholders will adapt to effects of climate change (Food and Agriculture [FAO] 2013, 2015).

Nigeria plans "Climate-Smart Agriculture" under the Nigeria's National Determined Contributions of COP21 Paris Agreement for which weather and climate information services are foremost safety nets. Adapting to impacts through access to timely weather forecasts and other adaptive mechanisms are foremost in Africa's policy dialogues and socio-economic development agendas (Oyekale 2015).

Policy makers' have thus considered several alternatives for enhancing farmers' adaptive capacity in the face of changing climatic parameters. A national strategy towards climate resilience, therefore, is to strengthen local resilience and adaptive capacity of vulnerable smallholders to facilitate their investments in Climate Smart Agriculture National Adaptation "Action" Plan towards a resilient agricultural sector (IFAD 2017; CCAFS 2015). One of the strongly identified pathways to meet this Action Plan is the utilization of weather and climate information to facilitate smallholder decisions for adaptation planning. Despite the inherent uncertainties that are associated with climate science and weather forecasting in making informed decisions on agricultural investments aimed at optimizing use of scarce resources available, there is no enough evidence of understanding gaps in the uptake of weather forecast information for long-term strategies of climate resilience, particularly in the Sub-Saharan Africa including Nigeria (African Climate Policy Centre [ACPC] 2011).

While studies in developed countries reveal that farmers benefit substantially from using seasonal forecasts (Mjelde et al. 2000), seasonal weather information has nevertheless been found to have very minimal impacts as it remains largely unutilized by smallholder farmers in Nigeria despite facing food deficits (Awolala 2018). This study analyzed major drivers of farmers' use of weather information as basis for adaptation decisions in the savannah area of Ondo State, Southwest of Nigeria. 


\section{Materials and Methods}

The study site was the Derived Savannah agro-ecology of Akoko North-West Local Government Area of Ondo State, Nigeria. Akoko North-West is located between latitudes $7^{\circ} 38^{\prime}$ and $7.6^{\circ} 27.6^{\prime} \mathrm{N}$ and longitudes $5^{\circ} 47^{\prime}$ and $5.8^{\circ} 38.4^{\prime} \mathrm{E}$ of the equator with an elevation of $486 \mathrm{~m}$ in Guinea Savannah agro-ecological zone (accessed from Google maps, 2017). Akoko North-West Local Government Area has an estimated population of 213,792 and covers a total area of $512 \mathrm{~km}^{2}$ (National Population Census 2006). Ondo State is located in the Southwest of Nigeria, entirely within the tropics with tropical climate broadly classified into rainy season (April-October) and dry season (November-March). Temperature throughout the year ranges between $21{ }^{\circ} \mathrm{C}$ to $30{ }^{\circ} \mathrm{C}$ and humidity is relatively high. The annual rainfall varies from $2,000 \mathrm{~mm}$ in the south to $1,150 \mathrm{~mm}$ in the north. Ondo State enjoys luxuriant vegetation with high forest zone (rainforest) in the south and subsavannah forest in the northern fringe (accessed from http:/www.coastalnews.com/profile/govern ment-profile profile) (Fig. 1).

Cross-sectional data used for this study were obtained using a structured questionnaire administered during a farm field survey of arable food crop farmers. Multistage sampling technique was used to select the respondents. In the first stage, Akoko North-West Local Government Area (LGA) was

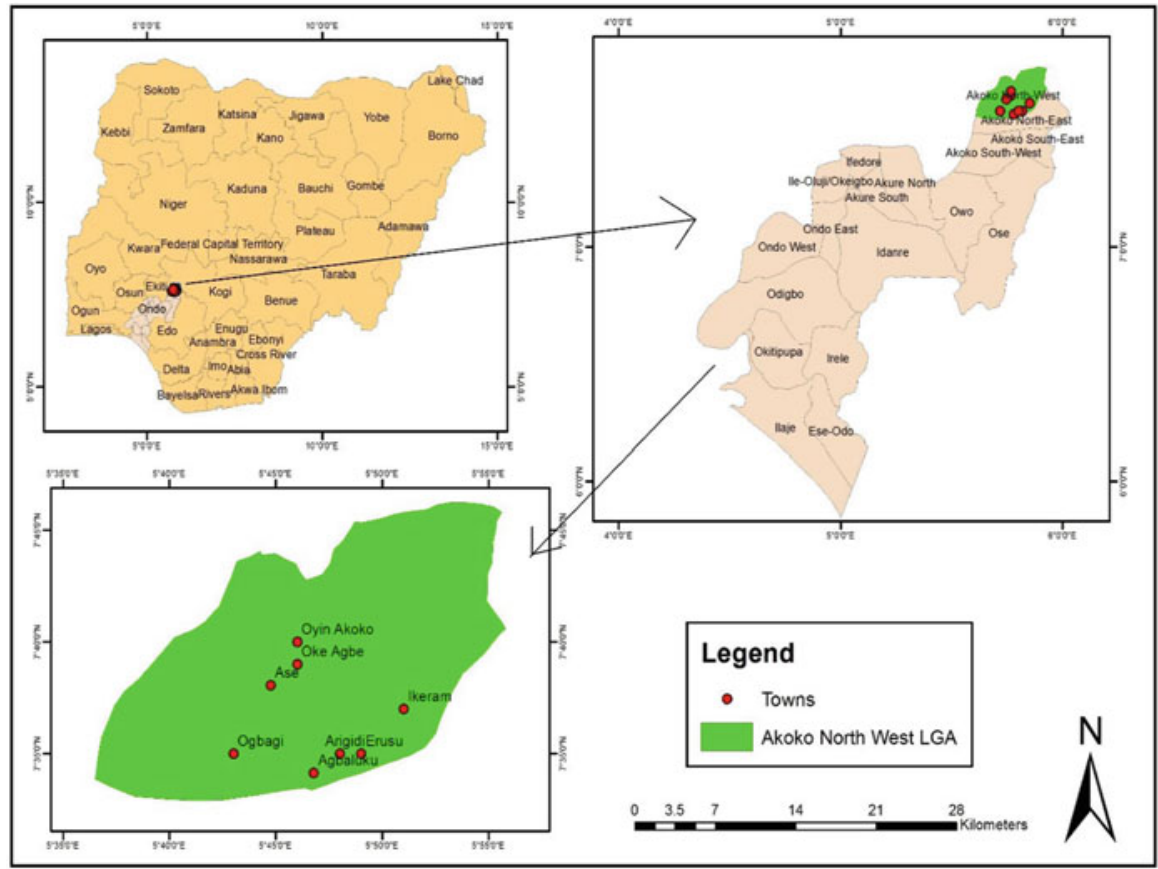

Fig. 1 Map of Akoko North-West showing selected villages in Ondo State 
purposively selected in guinea savannah agro-ecological zone of Ondo State given its dominance of major production of cereals and high dry vegetation. This zone is characterized by low rainfall and long dry period. The savannah area, however, has the potential for producing major food staples in meeting consumption and export requirement towards 2023 National Food Security Agenda in the State. In the second stage, eight farming communities were randomly selected from Akoko North-West LGA using a simple random sampling technique. The final stage involved the random sampling of 20 respondents in each farming community which resulted into a total of a hundred and sixty respondents sampled for the study.

\section{Econometric Model}

\section{Heckman Two-Step Procedure}

Heckman Probit Model was used to Analyse Determinant of Smallholders' Use of Weather Information in decision making processes. When a decision process by farmers to adopt an innovative strategy requires more than one step, models with two-step regressions are usually used to correct for the selection bias generated during the decision-making processes which implies the use of Heckman's Sample Selectivity Probit Model (Heckman 1976; Maddison 2006). For model specification, the first step involved the analysis of determinants of access to weather forecast information (selection model) and the second step was the smart decision taken, conditional on the first stage of access to weather information (outcome model), adapted from Awolala et al. and Oyekale (2015). The Probit model for sample selection assumes that there exists an underlying relationship. The latent equation is given by:

$$
y_{j}^{*}=x_{j} \beta+u_{1 j}
$$

Such that the binary outcome is only observed given by the Probit model as:

$$
y_{j}^{\text {probit }}=\left(y_{j}^{*}>0\right)
$$

The dependent variable is observed only if the observation " $\mathrm{j}$ " is observed in the selection equation:

$$
\begin{gathered}
y_{j}^{\text {select }}=\left(z_{j} \delta+u_{2 j}>0\right) \\
u_{1} \approx \mathrm{N}(0,1) \\
u_{2} \approx \mathrm{N}(0,1) \\
\operatorname{corr}\left(u, u_{2}\right)=\rho
\end{gathered}
$$


where, $\mathrm{x}$ is a k- vector of regressors, $\mathrm{z}$ is an m-vector of regressors; $u_{1}$ and $u_{2}$ are error terms jointly normally distributed, independently of $\mathrm{x}$ and $\mathrm{z}$ with zero expectations. When $\rho \neq 0$, standard Probit techniques apply to Eq. (3) give biased results. Hence, the Heckman Probit provides consistent, asymptotically efficient estimates for all parameters in such models (StataCorp 2003). Therefore, to analyze the determinant of farmers' utilization of weather forecast information in taking specific adaptations decisions, the marginal effects of a unit change in an independent variable on the probability $P(Z=1 \mid X=x)$ were obtained given that all other variables are held constant. It is mathematically expressed as:

$$
\frac{\delta P\left(Z_{i}=1 \mid x_{i}\right)}{\delta x_{i}}=\frac{\delta E\left(Z_{i}=1 \mid x_{i}\right)}{\delta x_{i}}=\varphi\left(x_{i}^{\prime} \beta\right)
$$

Table 1 presents variables that were analyzed in the Heckman two-step econometric model.

Table 1 Variable list for the econometric analysis

\begin{tabular}{|c|c|c|}
\hline Variables & Descriptions & Measurements \\
\hline \multicolumn{3}{|l|}{ Dependent variables } \\
\hline $\begin{array}{l}\text { Agricultural smart } \\
\text { decisions }\end{array}$ & $\begin{array}{l}\text { Smart agricultural decisions taken by farmers, } \\
\text { given weather information received (Yes }=1 \text { ) }\end{array}$ & \multirow[t]{2}{*}{$\begin{array}{l}\text { Yes }=1 ; 0 \text { if } \\
\text { otherwise }\end{array}$} \\
\hline $\begin{array}{l}\text { Farmer's access to } \\
\text { weather information }\end{array}$ & Farmer has access to weather information & \\
\hline \multicolumn{3}{|l|}{ Independent variables } \\
\hline Gender & Gender of farmer & $\begin{array}{l}\text { Female }=1 \\
0 \text { if otherwise }\end{array}$ \\
\hline Farming experience & Farming experience of household head & Number \\
\hline Farm size & Farm size cultivated & Hectares (ha) \\
\hline Credit & Access to agricultural credit finance & $\begin{array}{l}\text { Yes }=1,0 \text { if } \\
\text { otherwise }\end{array}$ \\
\hline $\begin{array}{l}\text { Agricultural extension } \\
\text { access }\end{array}$ & Access to agricultural extension services & $\begin{array}{l}\text { Yes }=1,0 \text { if } \\
\text { otherwise }\end{array}$ \\
\hline $\begin{array}{l}\text { Farmers Group } \\
\text { membership }\end{array}$ & Hold membership of Farmers Group & $\begin{array}{l}\text { Yes }=1,0 \text { if } \\
\text { otherwise }\end{array}$ \\
\hline $\begin{array}{l}\text { Access to weather } \\
\text { forecasts }\end{array}$ & If farmer receives weather information & $\begin{array}{l}\text { Yes }=1,0 \text { if } \\
\text { otherwise }\end{array}$ \\
\hline \multicolumn{3}{|l|}{ Weather information } \\
\hline Rainfall onset date & Rainy season onset date & $\begin{array}{l}\text { Yes }=1,0 \text { if } \\
\text { otherwise }\end{array}$ \\
\hline Cessation date & Rain cessation date & $\begin{array}{l}\text { Yes }=1,0 \text { if } \\
\text { otherwise }\end{array}$ \\
\hline \multicolumn{3}{|l|}{ Agricultural decisions } \\
\hline $\begin{array}{l}\text { Taking Smart } \\
\text { Agricultural decisions }\end{array}$ & Has taken smart adaptation practices & $\begin{array}{l}\text { Yes }=1,0 \text { if } \\
\text { otherwise }\end{array}$ \\
\hline
\end{tabular}

Source: Authors 2017 


\section{Results and Discussions}

\section{Drivers of Farmers' Use of Weather Information for Smart Decisions}

The result from the Heckman two-step regression estimates result in Table 2 reveals that access to credit is a major driver increasing farmers' propensity to adapt with climate-smart practices at 5\% level of significance while increasing access to information onset date, farm size, access to extension reduce farmers' their ability to take climate-smart actions in the derived savannah area. However, gender and access to agricultural extension service were major drivers positively facilitating access to weather information while farmers' experience negatively influence farmers' access to weather information in the derived savannah area of Ondo State, Nigeria.

Access to credit has a positive coefficient with the adoption of climate-smart practices $(p<0.05)$. An increase in access to credit will increase the likelihood that farmers would adopt climate-smart adaptation practices conditional on access to weather forecast information. It is viewed that with credit facilities, interested farmers will be able to bear the cost associated with climate smart practices. For instance, when there is a forecast that rainfall is likely to be unusually low, farmers can grow crops that are drought resistant and sensitive to water availability

Table 2 Heckman estimates of major drivers of farmers' use of weather information

\begin{tabular}{|c|c|c|c|c|}
\hline Variables & Coefficient & Standard error & $\begin{array}{l}\mathrm{Z} \text { - } \\
\text { value }\end{array}$ & $|\mathrm{P}>\mathrm{z}|$ \\
\hline \multicolumn{5}{|l|}{ Taken smart agricultural decisions } \\
\hline Access to rainfall onset date & -0.2677499 & 0.1405112 & -1.91 & $0.057^{\mathrm{a}}$ \\
\hline Access to rainfall cessation date & 0.1754594 & 0.1307748 & 1.34 & 0.180 \\
\hline Farm size in hectares & -0.0765449 & 0.0403879 & -1.90 & $0.058^{\mathrm{a}}$ \\
\hline $\begin{array}{l}\text { Access to agricultural extension } \\
\text { service }\end{array}$ & -0.0335072 & 0.3270912 & -0.10 & 0.918 \\
\hline Access to credit & 0.2943015 & 0.1500301 & 1.96 & $0.050^{\mathrm{b}}$ \\
\hline Constant & 0.6239116 & 0.5747793 & 1.09 & $0.0278^{\mathrm{b}}$ \\
\hline \multicolumn{5}{|l|}{ Access to weather information } \\
\hline Gender & 0.9495208 & 0.2676775 & 3.55 & $0.000^{\mathrm{b}}$ \\
\hline Farming experience & -0.0417005 & 0.0096622 & -4.34 & $0.000^{\mathrm{b}}$ \\
\hline $\begin{array}{l}\text { Access to agricultural extension } \\
\text { service }\end{array}$ & 0.736214 & 0.3857535 & 1.91 & $0.056^{\mathrm{a}}$ \\
\hline Constant & 0.3007832 & 0.4244483 & 0.71 & 0.479 \\
\hline Total observations & 160 & & & \\
\hline Censored obs & 99 & $\begin{array}{l}\text { Uncensored } \\
\text { obs }\end{array}$ & 61 & \\
\hline Prob $>\mathrm{chi}^{2}$ & 0.0621 & & & \\
\hline
\end{tabular}

Source: Field Survey 2017

${ }^{\text {a }}$ Statistically significant at 0.05

${ }^{\mathrm{b}}$ Statistically significant at 0.1 
to improve profit unlike farmers who also received forecast information but lack access to credit. Therefore, credit facility should be strengthened for smallholders' adoption of climate-resilient technology adaptation actions in the derived area.

Seasonal rainfall onset date and farm size both have negative coefficients with the adoption of climate-smart adaptation practices $(p<0.05)$. An increase in access to seasonal rainfall onset date, likewise increase in farm size, will reduce the likelihood that farmers would adopt climate-smart adaptation practices conditional on access to weather forecast information. These are important policy drivers that should be addresses because they signal danger to farmers' adaptation with climate-smart practices conditional on access to weather forecast information. There are certain socioeconomic and cultural factors which might be responsible for such findings. It is also believed that medium and large-scale farmers might be reluctant in taking climate-smart decisions due to the huge costs involved.

The positive coefficient of gender and access to extension service are both significant at $5 \%$ level $(p<0.05)$. The result implies that male farmers are more likely to have access to scientific weather forecast information unlike their female counterparts. It thus becomes obvious that this male farming population should be given attention as major pathway to ensure farmers' resilience with regards to utilization of scientific weather forecast information.

Likewise, increase in access to agricultural extension service, it will be more likely that farmers would have access to weather forecast information in the study area. This is because the role of agricultural extension is critical to move weather forecast information from weather service providers especially the Nigerian Meteorological Agency (NiMet) and other weather forecast agencies in other to ensure a return on investment by translating new knowledge into innovative practices which will enhance farmers' resilience.

Further results explained the negative coefficient of farmers' experience with access to weather forecast information $(p<0.05)$. As farmers' experiences increase, there is a declining likelihood that they will have access to scientific weather forecast information. This might be attributed to their over reliance on traditional experience and knowledge of monitoring weather with local indicators in the study area. This is another important policy variable indicating that there should be improvements in farmers literacy and awareness campaign to encourage the use of scientific-based weather forecasts information to help facilitate climate-smart adaptation actions other than traditional forecasting techniques in the dryland. Table 2 presents the econometric results of factors influencing the use of weather information for smart decisions in the study area.

\section{Conclusions and Policy Recommendations}

Access to rainfall cessation date has a positive significant effect on farmers' use of improved weather information. Increasing access to seasonal rain probabilities forecast through information sharing increases the likelihood that farmers will use improved weather information for smart production decisions. Weather services 
such as rainfall forecasts and advisory planting calendars based on length of growing season should be location specific and timely communicated by the Nigerian Meteorological Agency (NiMet) in a mode that is understood at farmers' level. Such information on rainfall cessation date is considered significantly helpful for farmers adaptation planning and resilience.

Credit also significantly facilitates farmers' use of weather information in taking climate-smart decisions. It is viewed that with credit facilities, interested farmers will strengthen their adaptive capacity to afford whatever transaction cost that might be associated with climate smart practices if they have adequate financial assistance. Better incentive-based credit facility should be developed as a farmer-oriented financial product to strengthen smallholders' decisions for climate-resilient technology actions in the dry land area. Similarly, Policy makers should ensure functioning financial institutional services especially rural access to bank credits and informal credits are available to help farmer's withstand unforeseen circumstances that may arise from investing in innovative climate smart practices.

In terms of access, male farmers were found to have more access to weather information. Agricultural decisions are traditionally considered as responsibility of the household head, and most of the times, it is the male gender. Therefore, weather information utilization could be more guaranteed when male farmers are used as an entry point to allow for quick and wider coverage among farmers given their strong influence as decision makers. Policy makers and agricultural stakeholders at the federal, state, and local government levels must ensure that rural education is provided for male household heads to fast-track local uptake of improved weather information as weather risk adaptation strategy.

Better access to agricultural extension services also increase farmers' likelihood to have access to weather forecasts. Agricultural Extension Department at the Ministry of Agriculture and Rural Development must ensure that periodic extension education and training services serve as opportunities to share updated information on weather with farmers and provide advisory services on smart agro-weather management technologies. A functional and effective extension service system has great potential in facilitating early action on weather risk management through climate smart practices by the increasing farming population in the derived savannah area of Ondo State, Nigeria.

These drivers should be considered for a review as strategies for implementing the National Climate Smart Agriculture Adaptation Plan (NCSAAP) in Ondo State, Nigeria, as stated in the revised National Agricultural Policy which targets agricultural livelihood resilience towards meeting the 2030 National Food Security Agenda.

\section{References}

African Climate Policy Center [ACPC] (2011) Assessment of Africa's Climatic records and recording networks including strategic for rescuing of climatic data. Working Paper 3 of the African Climate Policy Center (ACPC) Of United Nations Economic Commission for Africa (UNECA) under the Climate for development in Africa (Climdev Africa) programme 
Alston M (2013) Gender mainstreaming and climate change. Women's Stud Int Forum 47:1-8

Awolala DO (2018) Climate smart adaptations in the African tropics: scaling weather information for decision support outcomes in Nigeria savannahs. In: Leal Filho W (ed) Handbook of climate change resilience. Springer, Cham, pp 1-33. https://doi.org/10.1007/ 978-3-319-71025-9 169-1. Online ISBN 978-3-319-71025-9

Bryan E, Deressa T, Gbetibouo GA, Ringler C (2009) Adaptation to climate change in Ethiopia and South Africa: options and constraints. Environ Sci Pol 12:413-426

Climate Change, Agriculture and Food Security [CCAFS] (2015) Implementing climate-smart agriculture for enhanced food security and resilience. Progress report led by the International Center for Tropical Agriculture (CIAT) and other Research Centres

FAO (2011) Climate change and food systems resilience in sub-saharan Africa (eds: Ching LL, Edwards S, Scialabba NE-H). Office of Knowledge Exchange, Research and Extension, FAO, Rome

FAO (2013) Climate smart agriculture source book. Food and Agriculture Organization of the United Nations, Rome

FAO (2015) Barriers, incentives and benefits in the adoption of climate smart agriculture: enhancing agricultural mitigation within East Africa Dairy Development project (EADD) in Kenya. FAO, Rome

Heckman JJ (1976) The common structure of statistical models of truncation, sample selection and limited dependent variables and a simple estimator for such models. Ann Econ Soc Meas 5:475-492

IFAD (2017) IFAD Strategy and Action Plan on Environment and Climate Change: 2019-2025. Document: EB 2018/125/R.12.

Jones L, Carabine E (2013) Exploring political and socio-economic drivers of transformational climate policy: early insights from the design of Ethiopia's Climate Resilient Green Economy strategy. Research reports and studies. Overseas Development Institute, London

Lal R, Kraybill D, Hansen DO, Singh BR, Eik LO (2016) Research and Development Priorities. In: Lal R, Kraybill D, Hansen D, Singh B, Mosogoya T, Eik L (eds) Climate Change and MultiDimensional Sustainability in African Agriculture. Springer, Cham. https://doi.org/10.1007/ 978-3-319-41238-2

Maddison D (2006) The perception of and adaptation to climate change in Africa. Discussion Paper No. 10. Centre for Environmental Economics and Policy in Africa (CEEPA). University of Pretoria, Pretoria

Madzwamuse M (2010) Climate governance in Africa: adaptation strategies and institutions. Heinrich Böll Stiftung (HBS), Nairobi

Mjelde et al (2000) Climate change and multi-dimensional sustainability in African agriculture

Mugabe FT, Mubaya CP, Nanja DH, Munodawafa A, Gondwe P, Mutswangwa EA, Changonda C, Masere P, Makuvaro V, Dimes J, Murewi C (2010) Using indigenous knowledge for climate adaptation in Southern Zambia and South-Western Zimbabwe. Zimb J Sustain Dev Afr 11(2):237-256

NPC (2006) National Population Census Report, Nigeria

Oyekale AS (2015) Factors explaining farm households' access to and utilization of extreme climate forecasts in Sub-Saharan Africa (SSA). Environ Econ 6(1): 91-103

Sanni et al (2012) Traditional capacity for weather prediction, variability and coping strategies in the front line states of Nigeria. Agric Sci 3:625

Serna JM (2011) Drought Assessment Northern Eastern Kenya (Wajir East, South and Mandera). Northern Eastern Kenya Drought Assessment Report

StataCorp (2003) Stata base reference manual. Volume 4, G - M, release 8. Stata Corporation, College Station

UNDP (2011) Human Development Report 2011. Sustainability and equity: a better future for all. Palgrave Macmillan, New York

UNEP (2018) United Nations Environment Annual Report

Vermeulen S, Zougmore R, Wollenberg E, Thornton P, Nelson G, Kristjanson P, Kinyangi J, Jarvis A, Hansen J, Challinor A, Campbell B, Aggarwal P (2012) Climate change, agriculture 
and food security: a global partnership to link research and action for low-income agricultural producers and consumers. Curr Opin Environ Sustain 4:128-133

World Bank (2013) Weather and climate resilience: effective preparedness through National Meteorological and Hydrological Services (NMHSs) in the World Bank Development Report of Rogers DP, Tsirkunov VV (2013) Directions in development - environment and sustainable development. World Bank, Washington, DC

Ziervogel G, Zermoglio F (2009) Climate change scenarios and the development of adaptation strategies in Africa: challenges and opportunities. Clim Res 40(2-3):133-146. https://oi.org/ $10.3354 / \mathrm{cr} 00804$

Open Access This chapter is licensed under the terms of the Creative Commons Attribution 4.0 International License (http://creativecommons.org/licenses/by/4.0/), which permits use, sharing, adaptation, distribution and reproduction in any medium or format, as long as you give appropriate credit to the original author(s) and the source, provide a link to the Creative Commons license and indicate if changes were made.

The images or other third party material in this chapter are included in the chapter's Creative Commons license, unless indicated otherwise in a credit line to the material. If material is not included in the chapter's Creative Commons license and your intended use is not permitted by statutory regulation or exceeds the permitted use, you will need to obtain permission directly from the copyright holder.

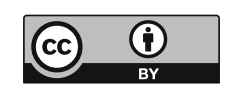

